\title{
ROBOTIC GASTRECTOMY: TECHNIQUE STANDARDIZATION
}

\author{
Gastrectomia robótica: Padronização técnica
}

\author{
Andre Roncon DIAS ${ }^{1 \oplus}$, Marcus Fernando Kodama Pertille RAMOS ${ }^{1 \oplus}$, Daniel Jose SZOR $^{1 \oplus}$, \\ Ricardo ABDALLA $^{1 \oplus}$, Leandro BARCHI ${ }^{1 \oplus}$, Osmar Kenji YAGI ${ }^{1 \oplus}$, Ulysses RIBEIRO-JUNIOR ${ }^{1 \oplus}$, Bruno \\ ZILBERSTEIN $^{1 \oplus}$, Ivan CECCONELLO ${ }^{1 \odot}$
}

\begin{abstract}
Background: Robotic gastrectomy is gaining popularity worldwide. It allows reduced blood loss and lesser pain. However, it widespread use is limited by the extensive learning curve and costs. Aim: To describe our standard technique with reduced use of robotic instruments. Methods: We detail the steps involved in the procedure, including trocar placement, necessary robotic instruments, and meticulous surgical description. Results: After standardizing the procedure, 28 patients were operated with this budget technique. For each procedure material used was: 1 (Xi model) or 2 disposable trocars (Si) and 4 robotic instruments. Stapling and clipping were performed by the assistant through an auxiliary port, limiting the use of robotic instruments and reducing the cost. Conclusion: This standardization helps implementing a robotic program for gastrectomy in the daily practice or in one's institution.
\end{abstract}

HEADINGS: Stomach neoplasms. Telesurgery. Robotic Surgical Procedures. Gastrectomy.

RESUMO - Racional: A gastrectomia robótica está ganhando popularidade no mundo. Ela permite menor perda sanguínea e menos dor. Entretanto, a curva de aprendizado extensa e os custos limitam seu amplo uso. Objetivo: Descrever nossa técnica padrão com uso reduzido de instrumental robótico. Métodos: Detalham-se todos os passos envolvidos no procedimento, incluindo posicionamento de portais, instrumentos robóticos necessários e descrição cirúrgica meticulosa. Resultados: Após a padronização do procedimento, 28 pacientes foram operados com essa técnica. Em cada procedimento foram utilizados: 1 (modelo Xi) ou 2 (Si) trocárteres descartáveis e 4 pinças robóticas. Grampeamentos e colocação de clips ficaram a cargo do auxiliar, reduzindo o número de instrumentos robóticos utilizados, diminuindo assim o custo. Conclusão: Essa padronização ajuda a implementar programa robótico de gastrectomia na prática diária ou em uma instituição.

DESCRITORES: Neoplasias gástricas. Telecirurgia. Gastrectomia. Robótica.

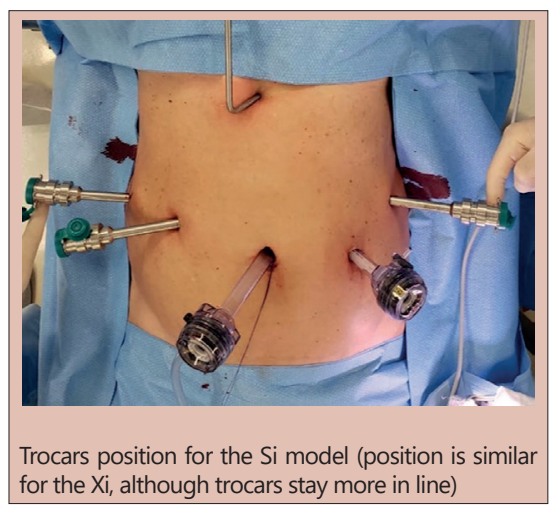

\section{Central messager}

Standardization of the robotic gastrectomy for gastric cancer reduces operative duration and abbreviates the learning curve. The number of robotic instruments used can be limited, reducing cost without jeopardizing results.

\section{Perspective}

Robotic gastrectomy for gastric cancer is a challenging and expensive procedure. The budget step-by-step approach presented here intents to help teams implement it more smoothly.

From the 'Instituto do Câncer, Hospital das Clínicas, Universidade de São Paulo, São Paulo, SP, Brasil (Cancer Institute, Hospital das Clínicas, University of São Paulo, São Paulo, SP, Brazil)

How to cite this article: Dias AR, Ramos MFKP, Szor DJ, Abdalla R, Barchi L, Yagi OK, Ribeiro-Junior U, Zilberstein B, Cecconello I. Robotic gastrectomy: Technique standardization. ABCD Arq Bras Cir Dig. 2020;33(3):e1542. DOI: /10.1590/0102-672020200003e1542

Correspondence

André Roncon Dias

E-mail: andreroncon@usp.br

roncon86@hotmail.com
Financial source: none

Conflict of interest: none

Received for publication: 30/01/2020

Accepted for publication: 03/04/2020 
INTRODUCTION

$\mathrm{R}$ obotic gastrectomy in gastric cancer is gaining worldwide acceptance and studies are confirming its safety and efficacy. However, its widespread use is still limited due to costs and the necessity for multidisciplinary team massive training.

Laparoscopic gastrectomy has an extensivelearning curve ${ }^{6}$ and many differences when compared to the open approach: critical view, instrumental manipulation, presentation, ergonomics, etc. Robotic access is considered by some as an enhanced laparoscopy ${ }^{11}$, and those with experience in minimally invasive gastrectomy show quick adaptation ${ }^{10,12}$. However, the access has its own particularities, with increased complications in the beginning and massive learning curve, despite laparoscopic expertise ${ }^{8}$.

Therefore, standardization is a key element to help implement robotic gastrectomy with reduced risk for patients. Alternatives to limit the cost are also desirable, especially in developing countries.

So, the objective of this article was to present a budget standardized technique for robotic D2 gastrectomy, using the Da Vinci system (Intuitive).

\section{METHODS}

\section{Technique}

Robotic material

1) One $12 \mathrm{~mm}$ disposable trocar (long, only for DaVinci $\mathrm{Si}$ Model); 2) one $12 \mathrm{~mm}$ disposable trocar (short); 3) three robotic $8 \mathrm{~mm}$ trocars (4 if Xi model); 4) one fenestrated bipolar forceps (robotic) or Maryland bipolar; 5) one harmonic scalpel (robotic); 6) one Cadiere (robotic); 7) one large needle driver (robotic)

\section{Positioning}

Patient is placed in supine position with $15^{\circ}$ reverse Trendelenburg. For cavity access and optics, a supraumbilical incision is made and pneumoperitoneum established with 12 $\mathrm{mmHg}$ pressure. Work trocars are placed as presented in Figure 1. Robotic arms 1 and 3 stay at the right side of the patient. Arm 2 and the assistant port are placed on the left side. The assistant is responsible for clipping and stapling, reducing the need for robotic instruments. An epigastric $5 \mathrm{~mm}$ incision is made and a liver retractor placed. The patient's cart is docked from the head when using the Si model, while Xi can be docked by the patient's right side leaving the head free.

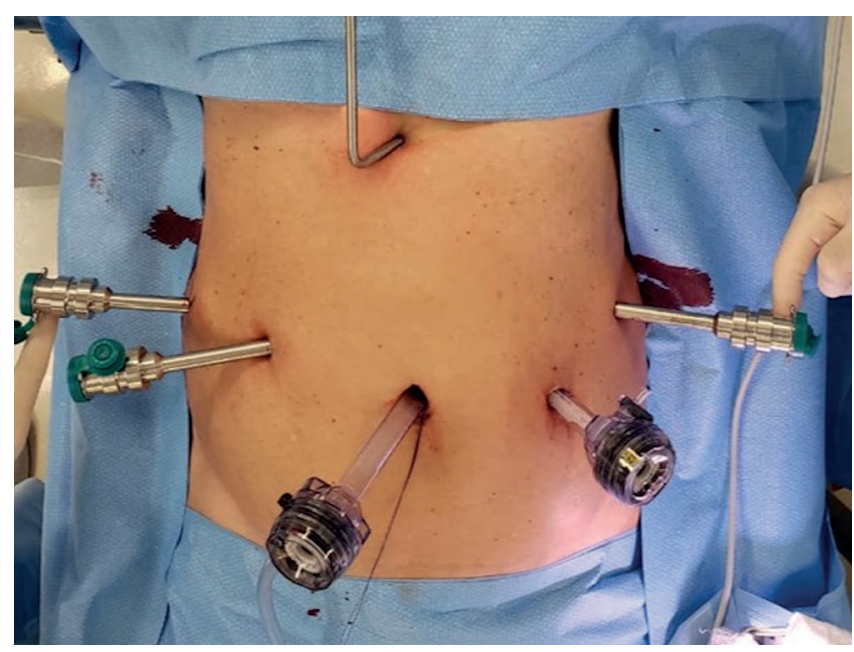

FIGURE 1 - Trocars position for the Si model (position is similar for the $\mathrm{Xi}$, although trocars stay more in line)

Instrumentation is performed with the harmonic scalpel on arm 1, fenestrated (or Maryland) bipolar forceps on arm 2 and Cadiere on arm 3. The forceps and the harmonic can be switched as needed. Arm 1 is controlled by the surgeon's right hand, 2 and 3 by his left hand. Trocar positioning is always checked for their remote center location.

\section{The procedure}

Cavity is inspected and the tumor identified whenever possible. For early lesions whose location in the gastric body leaves doubt about the extent of the gastrectomy we suggest marking its borders preoperatively with indocyanine green (Figure 2), since intraoperative endoscopy increases the surgical duration and requires undocking if using the Si model.

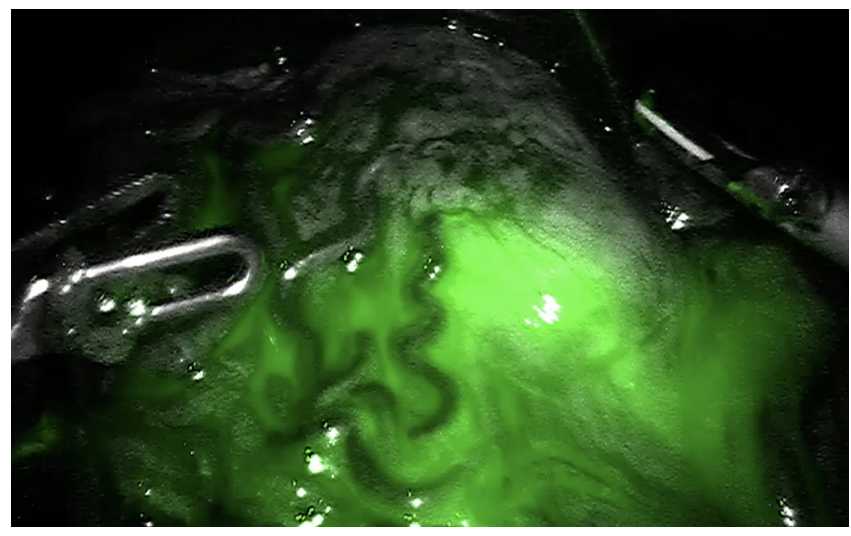

FIGURE 2 - Proximal margin determined by indocyanine green fluorescence

The procedure starts by mobilizing the omentum. For advanced cases it is removed en-bloc with the specimen, while in early lesions the gastrocolic ligament is sectioned approximately $3 \mathrm{~cm}$ from the gastric arcade along the greater curvature.

Dissection is carried out in anti-clockwise fashion and the left gastro-epiploic vessels clipped and sectioned. For subtotal gastrectomy the greater curvature is prepared at least at the level of the first short gastric vessel (this may vary according to the lesion's location and proximal margin required), while in total gastrectomy dissection stops after clearing the left diaphragmatic pilar.

Next, dissection goes clockwise until the pancreatic head and the duodenum are exposed. The pancreatic plateau is freed from the antrum and, whenever possible, lymph node station 8a dissected exposing the common hepatic artery. The gastroduodenal artery is dissected and the right gastroepiploic vessels clipped and sectioned, this clears lymph node station 6 .

Dissection progresses to the suprapiloric region and after determining an adequate margin the duodenum is transected with a linear stapler operated by the assistant.

The hepatic hilum is cleared in its anterior aspect, removing station 12a and exposing the proper hepatic artery. Dissection is limited to the right by the bile duct. The procedure progresses clockwise with the stomach being pulled to the left of the patient. Dissection continues along the common hepatic artery and the left gastric vein is clipped and sectioned. Lymph node $11 \mathrm{p}$ is then removed en-bloc with the specimen.

Station 9 is cleared; the gastrohepatic ligament divided and the left gastric artery sectioned after ligation with titanium or polymer clips (choice is based on its caliber). Nearly $10 \%$ of the patients have an accessory left hepatic artery (branch from the celiac trunk), it is spared whenever possible, removing the lymph nodes and dividing only the gastric branches (Figure 3).

For subtotal gastrectomy, the lesser curvature is cleared from stations 1 and 3 and the stomach sectioned with linear stapler. Reconstruction is performed in Roux-en-Y. The jejunum is then divided approximately $15-20 \mathrm{~cm}$ from the duodenojejunal flexure (Treitz) and an antecolic gastrojejunal anastomosis made with linear stapler on the gastric posterior wall. The stapler's entry hole is closed in one plane of running suture with 3-0 polydioxanone. Transmesocolic fashion is chose when tension is observed or when 
the colic mesentery is accidentally opened during dissection. The alimentary loop is left with $60 \mathrm{~cm}$ and a side-by-side anastomosis performed with the biliary jejunal loop.

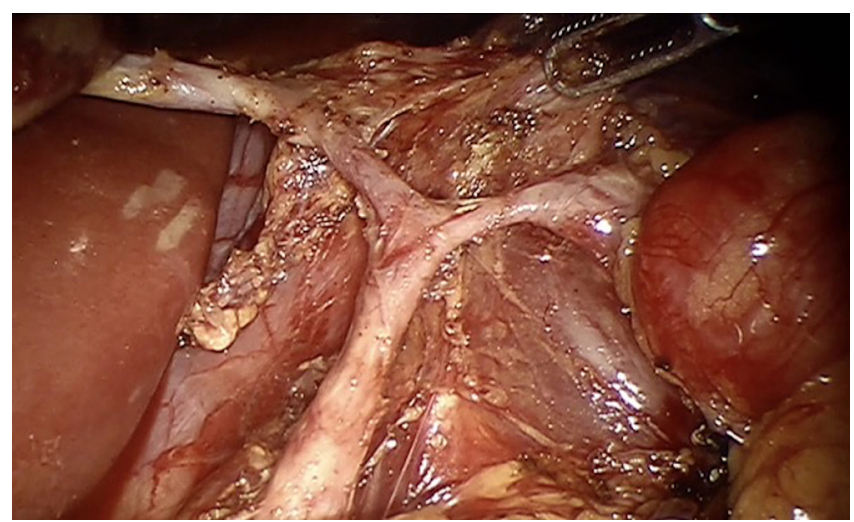

FIGURE 3 - Artery from the celiac trunk branching into left gastric artery and left accessory hepatic artery

For total gastrectomy, the lesser curvature is left intact and the esophagus dissected. Lymph node stations $11 \mathrm{~d}, 10,19$, 20, 110 and 111 are only removed in selected cases ${ }^{1}$. Roux-in-Y reconstruction with transmesocolic fashion is performed. A sideby-side esophagojejunostomy is performed before sectioning both structures. This allows the stomach to be used for traction. A boogie calibrates the anastomosis and then the esophagus is sectioned by a stapler. The entry hole (partially closed when sectioning the esophagus) is closed by manual suture. Alternatively, the esophagus may be divided before the anastomosis and the entry hole may be stapled $^{3}$. When more extensive esophageal margin is required, the esophagus is divided and manual end-to-sideesophagojejunostomy performed in two planes (calibrated with a boogie). This anastomosis is always tested with methylene blue and mesenteric holes closed. Sixty centimeters below the esophagojejunostomy, a mechanical side-by-side enteric anastomosis is performed. The jejunum is divided and this anastomosis brought to the inframesocolic area.

In both subtotal and total gastrectomy, the mesenteric defects are closed and a drain is left over the duodenum and near the gastrojejunostomy or esophagojejunostomy. Specimen is retrieved by extending the supraumbilical port (preferred option in those with umbilical hernia) ${ }^{9}$ or by suprapubic incision. When margins require frozen section, the specimen is removed before reconstruction. Lymph node stations are carefully dissected in fresh and then fixed in Carnoy's solution for $12-24 h^{7,13}$.

\section{RESULTS}

Gastric cancer surgeons with laparoscopic experience and certified in robotic surgery extensively debated the instruments to be used and the technical approach. The first cases were performed in swine and then in patients under informed consent.

After the procedurewas standardized and the team acquainted with the method, the trocar placement and the surgical steps, 28 patients were operated in our institution.

For each procedure, 4 robotic instruments and 1 (Xi model) or 2 (Si) disposable trocars were used. The assistant performed all stapling and clipping through the auxiliary port.

At this time, we cannot share the surgical results, since after standardization, all patients operated were included in an ongoing randomized trial comparing robotic with open gastrectomy (ClinicalTrials.gov Identifier: NCT02292914).

\section{DISCUSSION}

Robotic access has the advantages of 3-D view, more degrees of movement and better ergonomics when compared to laparoscopy ${ }^{2,4,14}$. This translates in lesser blood loss and arguably in quicker and less painful recovery ${ }^{5}$. However, the learning curve, despite laparoscopic experience, and the cost are two main drawbacks that prevent robotic implementation.

Obviously, extensive experience with gastric cancer and massive team and individual acquaintance with the equipment are required not to jeopardize the oncological results or increase the complication rate when compared to open or laparoscopic approaches. Here we presented our standardized approach to help those interested in overcoming the difficult first steps, when small issues such as trocar placement may add considerable operative time or difficulty to the procedure. We also limit the number of robotic instruments used to allow a budget option, which is extremely important in countries such as Brazil.

The approach presented here is the result of our experience, first with laparoscopic surgery, then with robotic procedures in swine and, only then, in patients under informed consent. It evolved over the last six years, thanks also to group discussions and debates with international peers.

\section{CONCLUSION}

Standardization of the robotic gastrectomy for gastric cancer reduces operative duration and abbreviates the learning curve. The number of robotic instruments used can be limited, reducing cost without jeopardizing results.

\section{REFERENCES}

1. Association JGC. Japanese gastric cancer treatment guidelines 2014 (ver 4). Gastric Cancer. 2017;20(1):1-19.

2. Barchi LC, Jacob CE, Bresciani CJ, Yagi OK, Mucerino DR, Lopasso FP, et al. Minimally invasive surgery for gastric cancer: time to change the paradigm. Arq Bras Cir Dig. 2016;29(2):117-20.

3. BarchiLC, JacobCE, FrancissMY,KappazGT, RodriguesFilhoED,Zilberstein B. Robotic digestivetractreconstruction aftertotal gastrectomyforgastric cancer: a simple way to do it. Int J Med Robot. 2016 Dec;12(4):598-603. doi: $10.1002 /$ rcs. 1720.

4. Barchi LC, Souza WP, Franciss MY, Ramos MFKP, Dias AR, Hyung WJ et al. Oncological Robot-Assisted Gastrectomy: Technical Aspects and Ongoing Data. J Laparoendosc Adv Surg Tech A. 2019.

5. Chen K, Pan Y, Zhang B, Maher H, Wang XF, Cai XJ. Robotic versus laparoscopic Gastrectomy for gastric cancer: a systematic review and updated meta-analysis. BMC Surg. 2017;17(1):93.

6. Dias AR, Jacob CE, Ramos MFKP, Pereira MA, Szor DJ, Yagi OK, et al. Laparoscopic D2 Gastrectomy for Gastric Cancer: Mid-Term Results and Current Evidence. J Laparoendosc Adv Surg Tech A. 2019:29(4):495-502.

7. Dias AR, Pereira MA, Mello ES, Zilberstein B, Cecconello I, Ribeiro Junior $U$. Carnoy's solution increases the number of examined lymph nodes following gastrectomy for adenocarcinoma: a randomized trial. Gastric Cancer. 2016;19(1):136-42.

8. Kim MS, KimWJ, HyungWJ, KimHI, HanSU, KimYW, etal.Comprehensive Learning Curve of Robotic Surgery: Discovery From a Multicenter Prospective Trial of Robotic Gastrectomy. Ann Surg. 2019.

9. Lupinacci RM, Dias AR, Kondo A, Lupinacci RA. Inguinal hernia orifice for specimen extraction after laparoscopic resections. Surg Innov. 2012;19(1):NP1-4.

10. Norero E Quezada JL Cerda J Ceroni M, Martinez C Mejía R et al. Risk factors for severe complications after gastrectomy for gastric and esophagogastricjunctioncancers.ArqBrasCirDig.2019Dec20;32(4):e1473.

11. Obama K, Kim YM, Kang DR, Son T, Kim HI, Noh SH, et al. Long-term oncologic outcomes of robotic gastrectomy for gastric cancer compared with laparoscopic gastrectomy. Gastric Cancer. 2018;21(2):285-95.

12. Park SS, Kim MC, Park MS, Hyung WJ. Rapid adaptation of robotic gastrectomy for gastric cancer by experienced laparoscopic surgeons. Surg Endosc. 2012;26(1):60-7.

13. Pereira MA, Dias AR, Faraj SF, Cirqueira CoS, Tomitao MT, Nahas SC, et al. Carnoy's solution is an adequate tissue fixative for routine surgical pathology, preserving cell morphology and molecular integrity. Histopathology. 2015;66(3):388-97.

14. Pirolla EH, Patriota GP, Pirolla FJC, Ribeiro FPG, Rodrigues MG, Ismail LR, et al. Inguinal repair via robotic assisted technique: literature review. Arq Bras Cir Dig.. 2018 Dec 6;31(4):e1408. 